\title{
Relevance and Strategies for Knowledge Sharing and Growth among Library and Information Sciences Educators: A Case of Selected Institutions in South- East Nigeria
}

\author{
Ifeyinwa Blessing Okoye (PhD) \\ ifeyinwa.okoye@futo.edu.ng \\ Agim Nneka \\ nneka.agim@futo.edu.ng \\ Abanum Rosemary C \\ rosemary.abanum@futo.edu.ng \\ Ezenwa Ezinne .N \\ ezenwaezinne@futo.edu.ng \\ Ndu Maria .O \\ ndu.maria@futo.edu.ng \\ Chikodi Nwakwuo L \\ chikodi.nwakwuo@futo.edu.ng \\ Federal University of Technology, Owerri, Imo State, Nigeria
}

\begin{abstract}
The teaching of Library and Information science at various institutions in Nigeria requires proper and adequate knowledge sharing, not only for sustainability but to guarantee the production of quality graduates in line with the international best practices. This paper therefore focuses on knowledge sharing, its retention and relevance to growth. Specifically, four research questions were formed to address the objectives of the work. The responses from the respondents gave rise to the strategies adopted in addressing some challenges in knowledge retention with reference to Library and information science profession. The population of the study was eighty-five (85) from six (6) selected Institutions in south east Nigeria. Questionnaire was the instrument used, while description and inferential statistics was for data analysis. The study came up with the following strategies as the recommendation to the study which include ensuring that the Library and Information educators should endeavor to move with the latest development and new skill in the profession through capacity building and in-house trainings. The Associations of various bodies in the profession should ensure that from time to time they come together to review and update their strengths and limitations and as to address as appropriate if need arises.

Keywords: Knowledge sharing, Library and Information Educators, Library and Information graduates, Economic development, Information Resources and Knowledge retention.

DOI: $10.7176 / \mathrm{IKM} / 12-2-04$

Publication date: February $28^{\text {th }} 2022$

Introduction:

Centuries have come and gone, it is worthy to note that human existence survive on knowledge sharing emanating from individuals, groups and organizations through their ideas, views, interactions, experiences, attitudes and challenges acquired overtime irrespective of the source, when and how. Knowledge sharing and its retention are important aspects of human existence especially in academics where collaboration in research is required. In any educational set up, knowledge sharing enables academics to develop flare for research and other potentials. According to Van den Hoof and De Ridder (2004), knowledge sharing is a process where individuals mutually exchange their knowledge and jointly create new knowledge. This definition connotes that knowledge sharing process consists of donating and collecting aspects of sharing. Knowledge being an essential commodity, has the capacity to transform the world in a positive or negative manner, and for this reason, one should be guarded during exchange and sharing. However the advancement and development witnessed "today" in this $21^{\text {st }}$ century, is a proof of knowledge sharing which is retained and transformed into use for the betterment of the society or otherwise as put up by $\mathrm{Ng}$ 'etich (2004) that information that has economic gain and security threatening capacity need not be shared. The cross- transmission of knowledge, these the Library does through a systematic acquisition of various type of resources and facilities which is provided to assist in creation of new knowledge by easy access and to the upward transfer of the existing knowledge through teaching and research by those involved. Ideally, the
\end{abstract}


society cannot progress without sharing of knowledge through learning, teaching and research. This transmission of knowledge has a multiple effect because the more existing knowledge is transmitted, the more it is shared and the more new knowledge is created. Knowledge is the only resources known to man that is inexhaustible. Knowledge sharing has given rise to a qualitative collaborative research which is being witnessed "today" by various groups and individuals especially among the academic folk. Suffice it to say that collaborative output of any research is more effective. This supports the view of Janssan (2014) that collaboration models actively encourage knowledge sharing across social collaborations.

Similarly in the business world, knowledge sharing has been seen to be more effective in its operations and management, for instance it has been discovered that multinational companies has proven to be more successful than a one-man business outfit and this justifies its conglomerate nature as more knowledge are shared among the involved groups.

Various studies deplete that most knowledge output found in many forms in almost all the fields at different libraries today are products of retained knowledge. Invariably, knowledge is a complex concept to define, but a cognitive product. However, Bergeron (2003) defines it as information that is organized, synthesized or summarized to enhanced comprehension, awareness, or understanding. Basically knowledge can only be share when it is adequately retained. Retained knowledge can also be shared through these broad formats manually, electronically and physically (teaching/discussions), which is summed up as follows published works, articles, books, journals, ephemeral materials; social media such as blog, whatsApp, facebook, instagram, twitter, zoom, Linked-in, discord, telegram, skype, emails and so on; physical interactions, group discussions, face-to-face interactions and so on. It is understood that an individual plans his life more, after critical understanding of his situation with the help of the knowledge acquired and retained by him through education, personal experiences and even in profession, more so, knowledge and understanding of situations and subjects helps an individual live his life in a fulfilled and meaningful manner. Acquisition of knowledge is said to be an important human aspect, remove knowledge sharing the entire system crumbles and sustainability becomes a mirage. Note that the future of any country lies within the domain of the quality of the knowledge retained by the workforce. The role knowledge plays in the personal and professional lives of people have made individuals and organizations go to the breadth and width of the world in search of it.

Given that knowledge has no boundary, it could be generated and shared among different groups. However, the significant roles the University Lecturers play in teaching, learning and research are enormous, as they are poised to bring transformation in the growth and development of the society through effective production of marketable graduates that will efficiently manifest and display the knowledge they have acquired and retained from their lecturers in their various areas of specialization. Consequently, the challenges faced by the Library and Information educators in Nigeria in producing quality graduates are exponential, as it becomes imperative to be greatly involved in adequate knowledge sharing among fellow professionals and otherwise to breakthrough. In addition to brace up with the new trends, the role of Lecturers in the University system is to teach, engage in community service and conduct research in their respective fields of specialization as well as involve in other academic activities such as publishing of academic papers, collaboration and sharing of information with colleagues in order to expand the frontiers of scholarship and knowledge in general (Aliyu and Dawha 2015). A study by Imhonopi and Urim (2011) pointed out that Academics in tertiary Institutions in developed countries engage in active collaboration and knowledge sharing among those within the same areas of specialization and as well as those that are outside their areas of specialization. This shows that knowledge has no wall and interdisciplinary sharing of knowledge make them academically viable and visible globally.

Holistically, knowledge not retained cannot be shared and that which are not shared cannot spur new idea and may not be considered as potential for creation of new knowledge. This justified why Ikhsan and Rowland (2004) emphasize that the beauty of knowledge sharing is that it grows, when it used and shared with another, and depreciates in value when it is kept to oneself.

\section{Statement of Problem.}

In spite of the fact that Library and Information science Educators are poised to make strategic impact in the realization of various Institutions' mandate which mainly centers on quality learning, teaching and research for economic growth and development. And despite the evolution and evolving nature of knowledge sharing in the $21^{\text {st }}$ century. However, it has been observed that these Educators have not fully aligned themselves with the type of knowledge to share and the method on how to share the knowledge, on this note therefore the effect on the educators, students as well as the challenges accompanied with it becomes enormous or otherwise. It is on this premise that this study is aimed to examine what the library and Information educators have done so far, for effective knowledge sharing in the bid to guarantee the production of quality graduates in line with international best practices considering its benefits on the society in terms of growth and development. 


\section{Research Questions.}

What type of knowledge resources do you share among Library and Information Educators?

In what ways do you share the knowledge you have acquired among the Educators?

What are the effects of knowledge sharing among Library and Information Educators?

What are the Challenges you encounter while sharing knowledge?

\section{Literature Review.}

Knowledge sharing is one of the fulcrum of life, without it, life possibly becomes meaningless, no one lives without interaction irrespective of the means. However there are several ways and methods of information sharing and transmission but the most important aspect is having the ability to retain what is shared for the growth and development of the entire society. That notwithstanding, there are myriads of research on this subject "knowledge sharing and its retention" but this work will confined itself on just a few because knowledge is a complex concept to define. More so, the purposes for which knowledge sharing was established in several institutions and organizations are diverse in nature and form. The essence of the entire idea was to create new knowledge or exploit existing knowledge that is why Van den Hooff and de Ridder (2004) defined knowledge sharing as the process where educators mutually exchange their knowledge and jointly create new knowledge. This implies that knowledge sharing process consists of 'donating' and 'collecting' aspects of sharing. According to them, knowledge 'donating' means communicating to others what one's personal intellectual capital is, while knowledge 'collecting' means consulting colleagues in order to get them to share their intellectual capital. Hong, Suh and Yoo (2011) in Collence Rexwhite and Josiline (2019) describe knowledge sharing as the process by which knowledge held by an individual are converted into forms. Similarly, Renzl (2008) in Muhammed, Enehe \& Abdulkareen (2019) defined knowledge sharing as a reciprocal process of knowledge exchange, and thus entails contributing, as well as accumulating knowledge from the mass. The knowledge 'donating' aspect essentially is similar to the mainstream definitions of knowledge sharing. However, the knowledge 'collecting' aspect seemed to receive less attention from the researchers in certain areas. Therefore, when it comes to sharing knowledge, some people can be quite reserve in expressing their ideas and opinions, much less voluntarily offering their knowledge to other people. In another development, other countries which are also considered as having a collectivistic culture but having problems as far as "knowledge sharing" is concerned is China (Hutchings \& Michailova, 2004). Managing knowledge entails knowledge identification, acquisition, development, sharing and distribution, utilization and retention (Probst, Raub \& Romhardt 2000). However, a study by Michailova and Husted (2003) revealed that there are five reasons why educators are reluctant to share knowledge. The reasons includes (i) the fear of decrease personal value, (ii) cost involved, (iii) uncertainty of how the receiver will use the shared knowledge, (iv) accepting and respecting a strong hierarchical and formal power, and (v) actual negative consequences of sharing knowledge with colleagues. On the other hand, most literatures categorized knowledge into two major forms; tacit and explicit (Nonaka \& Takeuchi, 1995). According to Bergeron (2003), explicit knowledge is the type that can be easily explained and codified, and are available in books, manuals and other types of publications. Tacit knowledge, on the other hand, is the type that is difficult to verbalize and codify because it is ingrained at a subconscious level. Yu and Zhou (2015) in Collence,,Rexwhite \& Josiline (2019) highlighted four types of tacit knowledge sharing processes as the peer review, the learning community, the academic conferences and thumb -a lift whereby tacit knowledge is shared through online platforms.

However, according to Ratcliffe-Martin, Coakes and Sugden (2000) in Muhammed, Enehe \& Abdulkareen (2019) LIBs education fails to recognize the importance of knowledge as a strategic resource. As libraries operate in the knowledge era they must focus on retaining their institutional knowledge both in the tacit and explicit format. For instance, the retention and management of knowledge enhances performance and may benefit institution by:

- $\quad$ facilitating better decision-making capabilities

- $\quad$ reducing 'product' development cycle time (i.e. curriculum development and research)

- $\quad$ improving academic and administrative services

- $\quad$ reducing costs

- $\quad$ preserving corporate memory

Combating staff turnover by facilitating knowledge capture and transfer (Kidwell, Vander Linde \& Johnson 2000) in Muhammed, Enehe \& Abdulkareen (2019). Essentially, the beauty of knowledge sharing is that knowledge grows when it is retained, used and shared with another, and it depreciates in value when it is kept to oneself. Moreso, as a result of knowledge sharing, the intellectual make-up locked up in their hearts and minds can be sustained and retained for library and information science educators in Nigeria. Therefore, it is important to know that knowledge sharing can be retained and grow among educators if proper avenues are created for the process.

Notably, if institutional educators engage in knowledge sharing, the institution can avoid redundancy in knowledge production, and at the same time ensure the diffusion of best practice throughout the education (Husted 
\& Michailova, 2002). Besides that, Husted and Michailova (2002) also claimed that the systematic sharing of knowledge among institutional members enables the institution to solve problem by making relevant personal knowledge available to the problem solving process regardless of where the knowledge is originally obtained and stored in the institution. Based on the conceptual study, knowledge sharing can be synthesized into useful knowledge for organizational progress as measured by indicators: seeking new information, increasing the ability of organizational members, disseminating information, applying knowledge new, feedback, and develop intellectual capital. Yuniarsih, kunendu \& Wibowo (2018).

Globally, employability now implies being aware of the dynamic world of work and taking responsibility for one's own career and personal development as well as lifelong learning needs (Blair, 2000), innovation can only be realised through knowledge sharing for professional growth because Library and Information Science (LIS) landscape in academic libraries is experiencing rapid changes which requires effective strategies through team work.

Igbinova and Osuchukwu $(2018,120)$ note that sustainable development goals (SDGs) agenda spurred a shift in discourse with regards to development in general, and this has in turn resulted to the upsurge of knowledge generated in various areas of sustainable development. The authors argue that the constant increase in knowledge necessitates the need for knowledge management (KM) within knowledge sharing (KS) interface, thus, leveraging knowledge for positive gain. Ryu, Ho and Han (2003) viewed knowledge sharing as the behaviour of an individual towards dispersing their accumulated knowledge and information. The accumulated knowledge and information could have been obtained either from other colleagues, or possibly from experiences in the work place, training, conferencing and interactions within and outside the organization. The infusion of communications work better when several participants are involved through the provision and acquisition of knowledge within and outside the organisation (Usoro, Sharratt, Tsui and Shekhar, 2007). However the sharing of knowledge becomes feasible when value is placed on what it is meant for (its use), than when it is not used (Ikeknwe and Igbinovia 2015). This indicates that people always value what they spend energy or money on. The regular knowledge sharing platform involves engagement in several activities that would make people to interact and discuss related issues that bothers on the organisation and their professional growth. In most countries, there are two groups of academic librarians and these consists of those in Polytechnic and Teachers Colleges and Universities. These educators have organised themselves into a consortium which not only serves as platform for resource sharing but knowledge sharing for their academic advancement and uniformity in the way they carry out their academic pursuit. These was also emphasized by the 1994 IFLA/UNESCO Public library manifesto where they emphasised the importance of continuous professional education. The essence of the continuous professional education is to have smooth workplace learning that serves as the basis for delivering quality library services. The responsibility of continuous learning rests on the individual, organisation and professional associations. IFLA Guidelines for Continuing Best Professional Development Principles and Best Practices (2016) place responsibility for ongoing learning, based on regular assessment, on the individual practitioner.

\section{Methodology.}

The study adopted descriptive survey design with a population of eighty- five (85), from five selected institutions in south east zone Nigeria. A well designed questionnaire was used to elicit information from all Library and Information educators from these institutions. Out of eighty-five (85) questionnaires, seven-five (75) were returned for use amounting to $63.8 \%$ response rate. Mean value was used to answer the research questions and percentages was also used to analyzed population from various institutions.

A higher value will indicate a positive response than a lower one .The mid- point is

$$
2.50 \text { i.e } \frac{1+2+3+4}{4}=\frac{10}{4}=2.5
$$

This means that, items up to the value of 2.50 were rated Agree while those less than 2.50 were rated Disagree.

Table 1: The population of Library and Information Science Educators in Selected Institutions in South East zone

\begin{tabular}{|l|c|l|}
\hline Institutions & Population & Percentages \\
\hline Nekede Polytechnic, Owerri & 13 & $11.5 \%$ \\
\hline Nnamdi Azikiwe University & 18 & $15.3 \%$ \\
\hline Micheal Opara University of Agriculture & 10 & $8.5 \%$ \\
\hline University of Nigeria Nsukka & 15 & $12.8 \%$ \\
\hline Abia State University & 12 & $10.2 \%$ \\
\hline Imo State University & 17 & $14.5 \%$ \\
\hline
\end{tabular}

From table one (1), on the population of the respondents, Educators from Nekede polytechnics had $11.5 \%$, Nnamdi Azikiwe educators had $15.3 \%$ and $8.5 \%$ of the entire population involved in the study from Michael Opara University of Agriculture, Umudike participated in the study. University of Nigeria, Nsukka had 12.8\%, Abia State University, Uturu had $10.2 \%$ and finally $14.5 \%$ Educators participated in the study. 
Table 2: Types of Information Resources for Sharing among Library and Information Educators in Selected Institution in South East Zone.

\begin{tabular}{|l|l|l|l|l|l|}
\hline Information resources & SA & A & SD & D & MEAN \\
\hline Library guide & 8 & 15 & 37 & 18 & 2.2 \\
\hline Textbooks & 30 & 25 & 10 & 13 & 2.9 \\
\hline Journals & 40 & 23 & 11 & 4 & 3.2 \\
\hline Test/seminar & 17 & 12 & 28 & 21 & 2.3 \\
\hline Practical manual & 13 & 14 & 31 & 20 & 2.2 \\
\hline Project work & 33 & 31 & 6 & 8 & 3.1 \\
\hline Lecture Note & 20 & 38 & 17 & 13 & 2.7 \\
\hline Library orientation note & 14 & 28 & 14 & 22 & 2.4 \\
\hline Research work & 38 & 19 & 10 & 11 & 3.0 \\
\hline Public Lecture & 24 & 22 & 15 & 17 & 2.6 \\
\hline Inaugural Lecture & 33 & 31 & 8 & 6 & 3.1 \\
\hline Term paper & 30 & 25 & 9 & 14 & 2.9 \\
\hline Published articles & 32 & 23 & 13 & 10 & 2.9 \\
\hline Course Curriculum & 31 & 30 & 12 & 5 & 3.1 \\
\hline Past examination question papers & 22 & 24 & 17 & 15 & 2.6 \\
\hline Theses \& Dissertations & 25 & 21 & 12 & 20 & 2.6 \\
\hline Paper Presentations (Compendium) & 30 & 20 & 14 & 14 & 2.8 \\
\hline
\end{tabular}

Grand total 2.74

In table 2, from the information resources listed on the table those that identified library guide and practical manual as the types of information resources they share for knowledge retention and growth had a mean score of 2.2 each. Textbook, term papers and published articles had mean score of 2.9 each. Those that pointed out Journal as type of resources for sharing had a mean score of 3.2. And whopping mean score of 3.0 is for research work. Inaugural lecture, course curriculum and project wok had mean score of 3.1 each as types of information resources for sharing among educators. Past question papers, theses and dissertation are not let out among the resources they share among themselves with mean scores 2.6 each. Finally paper presentations had a mean score of 2.8 . The grand total of the mean score is 2.74 . Generally from the table two, given the grand total score of 2.74 it depicts agreement response meaning that it is above 2.50 .

Table 3: Methods of sharing the knowledge among Library and Information Science Educators.

\begin{tabular}{|l|l|l|l|l|l|}
\hline Ways of sharing the knowledge & SA & A & SD & D & MEAN \\
\hline Systematic dissemination of information (SdI) & 14 & 24 & 16 & 24 & 2.3 \\
\hline PDF/Google & 38 & 21 & 10 & 9 & 3.1 \\
\hline Other internet browsers & 23 & 32 & 10 & 13 & 2.8 \\
\hline Other social media & 40 & 32 & 2 & 4 & 3.3 \\
\hline Website Links & 33 & 31 & 8 & 6 & 3.1 \\
\hline Institutional Repository (IR) & 20 & 32 & 14 & 12 & 2.7 \\
\hline Researchgate Link & 19 & 24 & 15 & 20 & 2.5 \\
\hline Institutional Links & 25 & 30 & 10 & 11 & 2.8 \\
\hline E-mail & 30 & 25 & 10 & 13 & 2.9 \\
\hline Linkedin & 14 & 18 & 28 & 15 & 2.3 \\
\hline WhatsApp group chart & 42 & 20 & 8 & 8 & 3.2 \\
\hline Physical interactions & 38 & 19 & 10 & 11 & 3.0 \\
\hline Conferences, Workshops and Seminars & 39 & 18 & 13 & 8 & 3.1 \\
\hline Real time (Phone calls) & 30 & 25 & 10 & 13 & 2.9 \\
\hline Media communication & 14 & 18 & 31 & 15 & 2.3 \\
\hline Other forms of communication & 17 & 20 & 25 & 16 & 2.4 \\
\hline
\end{tabular}

Grand mean score 2.6

Above on the table (3) indicates the method of sharing the knowledge which the respondents identified social media as the best way to share the knowledge among the educators with a mean score of 3.3, followed by telegram group chart with 3.2, then PDF/Google, website links and conference/workshops with a mean score of 3.1. Physical interactions had a mean score of 3.0. The respondents that are of the opinion that other internet browsers, real time (phone), institutional links are ways to share knowledge and with mean scores $2.8,2.9$ and 2.8 respectively. Respondents for institutional repository and researchgate also had a mean score 2.7 and 2.5 respectively. Media communication had mean score 2.3 and finally the grand total of the Library and information educators that share knowledge for retention is 2.6. Summarily, the methods for sharing knowledge as responded 
by the educators are totally in agreement.

Table 4: Effect of Knowledge Sharing among Library and information Science Educators.

\begin{tabular}{|l|l|l|l|l|l|}
\hline Effect of Knowledge Sharing & SA & A & SD & D & MEAN \\
\hline To enhance collaboration among us & 40 & 30 & 4 & 4 & 3.3 \\
\hline For advancement in skill, idea and attitude & 50 & 28 & - & - & 3.6 \\
\hline To update ones Knowledge and understanding in the course & 51 & 27 & - & - & 3.6 \\
\hline To produce new knowledge in the field & 53 & 22 & 1 & 2 & 3.6 \\
\hline To strengthen the curriculum & 30 & 42 & 3 & 2 & 3.2 \\
\hline To produce marketable graduates in the profession & 52 & 26 & - & - & 3.6 \\
\hline To harmonize the curriculum for uniformity among the educators & 49 & 20 & 5 & 4 & 3.4 \\
\hline To identify the difference in the method of teaching, learning and research & 31 & 30 & 12 & 5 & 3.1 \\
\hline To correct anomalies & 34 & 28 & 7 & 8 & 3.1 \\
\hline For new discoveries in field & 30 & 42 & 2 & 3 & 3.2 \\
\hline $\begin{array}{l}\text { To facilitate the teaching \& learning of library and information science at } \\
\text { different institutions. }\end{array}$ & 50 & 28 & - & - & 3.6 \\
\hline
\end{tabular}

Grand mean score 3.6

On the table above, are the effect and the outcome of knowledge sharing among Library and Information Educators. Those that are of the opinion that knowledge sharing enhances collaboration among them had a mean score of 3.3 and those that stated that it advances their skill, idea, and attitude; update ones knowledge and understanding, and produces new knowledge in the field had mean score of 3.6. To strengthen curriculum and produces marketable graduates in the field had mean scores of 3.2 and 3.6 respectively. Library and Information Educator that are of the view that knowledge sharing helps in harmonizing uniformity and identify differences in teaching, learning and research also had mean scores of 3.4 and 3.1 respectively. Those for "correct anomalies" had a mean score 3.1 and those for "new discoveries in Library and information professional" had 3.2 and finally to facilitate the teaching and learning Library and Information Science at various Institutions. Generally the grand total score is 3.6 meaning that the responses on the effect of knowledge sharing are in agreement.

Table 5: Challenges encountered while sharing Knowledge among the Library and Information Science Educators.

\begin{tabular}{|l|l|l|l|l|l|}
\hline Challenges encountered while sharing Knowledge & SA & A & SD & D & MEAN \\
\hline $\begin{array}{l}\text { Funds to make the knowledge available among educators at various } \\
\text { institutions }\end{array}$ & 30 & 42 & 3 & 2 & 3.2 \\
\hline Lack of interest among educators & 24 & 22 & 15 & 17 & 2.6 \\
\hline Lack of competence & 25 & 22 & 20 & 11 & 2.7 \\
\hline Time factor & 31 & 30 & 10 & 7 & 3.0 \\
\hline Lack of sponsorship & 50 & 25 & 3 & - & 3.6 \\
\hline Lack of internet connectivity & 53 & 23 & 2 & - & 3.6 \\
\hline Lack of commitment among the educators & 17 & 20 & 16 & 25 & 2.3 \\
\hline Poor power supply to aid the information sharing facilities & 38 & 19 & 12 & 9 & 3.1 \\
\hline Financial constraint to share the information resources & 26 & 52 & - & - & 3.2 \\
\hline Lack of support from parent institution and stakeholders & 28 & 22 & 17 & 11 & 2.8 \\
\hline ICT incompetence among the educators & 24 & 22 & 12 & 19 & 2.6 \\
\hline Lack of ICT facilities to share knowledge & 30 & 25 & 14 & 9 & 3.9 \\
\hline Personal attitude of the educators & 25 & 34 & 11 & 8 & 2.9 \\
\hline Inability to connect and network with other educators & 38 & 19 & 11 & 10 & 3.0 \\
\hline
\end{tabular}

Grand mean score 3.0

In highlighting the challenges encountered in knowledge sharing the educators identified funds as one of the major problem with a mean score 3.2. "Lack of interest among educators" and "Lack of competence" had mean scores of 2.6 and 2.7 respectively. The educators that stated lack of sponsorship and lack of internet connectivity had mean score of 3.6 each. Those that are of the opinion that time factor and inability to connect and network with other educators has mean score of 3.0 each. "Lack of commitment among the educators" "Poor power supply" and lack of support from parent institution and stakeholders had mean scores of 2.3, $3.1 \& 2.8$ respectively. Some educators pointed ICT incompetence among the challenges with a mean score of 2.6 and some stated lack of ICT facilities to share knowledge (3.9) and also personal attitude has been identified (2.9) as a challenge to knowledge sharing among the library and Information science educators. The grand total score of the challenges on knowledge sharing is 3.0 meaning that their responses are in agreement.

Discussion of Finding

This study has been able to identify various types of information resources that are mostly shared among the 
Library and Information science educators at various institutions in South East. From the outcome of the study, it was discovered that project work, inaugural lecture and course curriculum had the highest mean score of (3.1) each, followed by research work, published articles, textbooks 2.9 each and so on. The least of the information resources shared among the educators are Library guide, this may be because most of these institutions under study do not have equipped library like others, as to have Library guide. One would guess with the sharing of these information resources, it will somehow assist the provision of information, which in-turn aid the circulation of knowledge for nation's growth and development.

On the other hand, apart from the type information resources shared among the educators, there are ways and other mediums to convey those information resources to each other irrespective of where the target groups are. This confirms why Bergeron (2003) defined knowledge resources as information that is organized, synthesized or summarized to enhance comprehension, awareness, or understanding. From the result of the analysis on the table, it was discovered that PDF/Google, website links and conference/workshop are the major ways used by Library and Information Science educators in sharing knowledge with the highest mean score of (3.1). Following the forgoing, others that recorded, are social media: whatsApp and telegram group chart. By the emergence of technology, they way and manner things are done and handled are evolving by day, majority of people finds it easy to send and receive information resources through these medium, at times they give links or web addresses depending on the usage and the user. Most often pictures, videos and graphics are sent out for practical aspect of the information resources for knowledge use. Interaction has been of great help in the conveyance of information for the purpose of acquisition of knowledge through asking questions for better understanding, it might be in physical form or through real time (Phone) use. Some even use other forms of media communication for example radio talk -show, zoom, television and youTube channels to convey knowledge to fellow educators or to their students as the case be.

Globally, the evolving nature of the entire life, ranging from the manual or indigenous way of life pertaining the way things are done and handled desire more to be explicitly explained. Life has been made so easy with the emergence of technology, people now stay in their comfort zones, conduct quality research, even send out questionnaires and get responses within a space of time through online connectivity. This was supported by Pan and Hovde (2010) that, professional growth is driven by technological imperative and by the element that librarians share with other professionals. Going by the outcome of the analysis on the effect of the knowledge sharing among the Library and information Science Educators in South East. For Knowledge sharing to flourish among academic librarians, thus resulting to intrinsic and extrinsic professional growth, the experiences and knowledge of librarians needs to awaken. (Collence, Rexwhite \& Josiline2019)

One can see that it has a lot of advantages, no one hates knowledge, the day one stops learning is the day one dies. Therefore the result shows that it advances ones skill, idea and attitude, it also update ones knowledge and understanding. Here through these knowledge sharing one advances in learning and update the existing knowledge, because nobody knows it all and no one is an epitome of all knowledge, we therefore need each other for adequate transfer of knowledge, its sharing and retention for growth and development. Imperatively, educators' greatest achievement is being able to produce marketable graduates that can be at par with professional best practices globally. And with adequate sharing of information resource, the curriculum will be strengthened and harmonized for uniformity, more so anomalies will be corrected among the group, thereby facilitating the mode of teaching, learning and the way research are conducted among Library and Information Science Educators at various institutions, for proper development, growth and nation's prosperity. Hence, Gelfand (1985) identified a number of activities that fall under the umbrella of professional development in LIS, namely: availing oneself of professional literature, attending professional seminars, workshops, symposia, participating in continuous professional development and enrolling for academic courses. All these are to strengthen their academic prowess in their various fields of interest especially in Library and information science field.

However, its glories are not without challenges, despite all the effect on the side of the Library and Information Science Educators, students, graduates and society at large. The Educators has at several times or at one time or other in the bid to share knowledge faced some "brick walls". From the study carried out, on the analysis it was discovered that funds, lack of internet connectivity, poor power supply, and personal financial constraint were the major challenges in sharing of these information. Some parent institution finds it difficult to support and sponsor them for conferences and workshops, without recourse on its effect on the students and for the national growth. Unfortunately some educators do not have interest, some are full of excuses and procrastinations, and these boils down to poor attitude to the use of ICT and lack of competence in the use of new skill. These were reiterated by the submission of Chugh (2018) states that, there are myriad factors that interfere with knowledge transfer. The tacit knowledge, for example, serves as fluid for hierarchical barriers. Therefore, the lack of a knowledge sharing culture, coupled with interest and peer trust, job insecurity, incentives and resources, institutional politics and technological tools are myriad factors that hinders knowledge sharing. In effect some Educators are not committed to their job, they do not care and does not want to know of any new trend in the profession. Some solely rely on the institution and the stakeholders to provide virtually everything needed for the 
sharing of knowledge, outside that, they cannot even sponsor themselves for conferences and workshop "talkless" of acquisition of personal computers.

\section{Conclusion}

Given the role information play in our society especially among the academic world and having knowledge acquisition as a product of information shared, however knowledge not properly retained cannot be shared. Unfiltered knowledge does not have the ability to be properly shared. A situation where one can comfortably transfer and exchange knowledge inform of collaboration is generally highly recommended in academics. Development and growth of the society is a product of quality research conducted. Therefore, quality research are mostly collaborative in nature, hence, a pure evidence of teamwork, where people bring up ideas and views in the production of new knowledge. However the educators of Library and Information Science are not left out of this "game". From the result of the study, many educators of Library and Information Science in south east zone were able to identify some of the Information resources they share among themselves and their students and the ones that are mostly shared which they found relatively important for knowledge advancement in the profession which one thinks need to be more adequate. More so, the conveyance of these knowledge becomes very imperative as it seems to find out the sources of certain knowledge. Notably, information cannot just move in isolation it has to be transmitted through a means such as systematic dissemination of information (SDI), web link, social media, realtime (phone) institutional repository and so on. And the essence of knowledge sharing are enormous as it stands to give credence to proper information retention which finds it ways to the making of new discovery in the field, harmonizing of the curriculum for uniformity and above all, the production of marketable graduates in Library and Information Science in Nigeria and beyond. Finally the challenges are also spotted, to be mostly lack of interest on the side of the educators, lack of competence, lack of support from the parent institutions and stakeholders and above all, network challenge, financial constraint and lack of facilities to share the knowledge retained.

\section{Recommendations}

The educators of Library and Information Science should endeavor to acquire and make available more information resources for sharing, if it entails subscribing or donating as gift to other educators in order to enhance collaboration in the profession among the group and these will in-turn help to advance growth and development for better of the society.

The stakeholders of these institution should create enable environment for the knowledge sharing through the provision of steady internet with constant power supply. As well as recognition of the educators that have made "waves" in affecting the lives of students and fellow educators in the profession.

By ensuring that the educators that fails to move with the latest development and new skill are encouraged to do so through capacity building and in-house training to keep them abreast on the happenings in the profession and to enhance their competence in knowledge sharing for growth and development.

Finally the Associations of the various bodies in the profession should ensure that all the Library and Information Science members all over the country or globally will be dully registered as members and should attend meetings as to find out and discuss their areas of strengths and limitations and finally find collective solutions to them and address them as appropriate.

\section{Reference}

De Ridder J.A (2019), Organisational Communication and Supportive employees. Human Resources Management Journal 14(3). 20-30,

Bergeron, B. (2003). Essentials of Knowledge Management, Hoboken, NJ: John Wiley and Sons.

Murtala Aliyu, Emmanuel Mk Dawha (2015)

Effect of information sharing on research and teaching activities of academic Scientists in Federal Universities in North East Nigeria. Journal of Nigerian Libraries vol 48 (1-2) 22-35

Dimhonopi and Um Urim (2011). The impact of internet services on the research output of Academic Staff of Select of Selected Universities in South- Western Nigerian. The Association of information Proffessional of Nigeria. 8 (1)

Ikhsan-syed, S.O.S and Rowland, F (2004) knowledge Management in the public Organisation: a study on the relationship between Organisational elements and performance of knowledge transfer. Journal of Knowledge Mangement, 8 (2),95-111.

Blair, L. (2000). Beyond the square: career planning for information professionals in the new millennium, New Library World, 101(4), pp. 175-80.

Chugh, R. (2018). Tacit Knowledge Transfer in Australian Universities: Exploring the Barriers and Enablers. In MATEC Web of Conferences (Vol. 210, p. 04054). EDP Sciences

Gelfand, J. (1985). Professional-development for reference and adult services librarians.402- 403.

Igbinovia, M.O. and Osuchukwu, N. P. (2018). Predictors of knowledge sharing behaviour on Sustainable 
Development Goals among library personnel in Nigeria. IFLA Journal, p.0340035218763445.

Ikenwe, I. J. and Igbinovia, M. O. (2015). Influence of knowledge sharing in reducing the spread of" hiv/aids" among adolescents in rural areas in Delta state, Nigeria. Kuwait Chapter of the Arabian Journal of Business and Management Review, 4(12), p.1-18.

International Federation of Library Associations (IFLA). (2012a). IFLA Code of Ethics for Librarians and other Information Workers http://www.ifla.org/news/ifla-code-of-ethics- for-librarians-and-other-informationworkers-full-version

Pan, J. and Hovde, K. (2010). Professional development for academic librarians: Needs, resources, and administrative support. Chinese Librarianship: an International Electronic Journal, 29.

Ryu, S., Ho, S. H., and Han, I. (2003). Knowledge sharing behavior of physicians in hospitals.

Expert Systems with Applications, 25(1), 113-122.

Usoro, A., Sharratt, M. W., Tsui, E., and Shekhar, S. (2007). Trust as an antecedent to knowledge sharing in virtual communities of practice. Knowledge Management Research \& Practice, 5(3), 199-212.

Collence, Rexwhite \& Josiline (2019) Knowledge sharing Proffessional Growth: View from Academic Librarians in Zimbabwe. Library Philosophy and Practice. Available https://digitalcommons.unl.edu/libphilprac

Muhammed, S.A; Enehe, S.A and Abdulkareem (2019) Knowledge sharing for Knowledge retention and Growth. International journal of Academic Library and Information Science. academicmicresearch Journal

Yunisarsih, T; Kunendi \& Wibowo (2018) The Influence of knowledge sharing on Academic performance. Advances in Economics, Business and Management Research, vol 117 AtlantisPress

Bergeron, S. E. (2003). The role of transformational and transactional leadership in creating, sharing and exploiting institutional knowledge. Journal of Leadership and Institutional Studies, 9, (4), 32-44.

Probst, Raub \& Romhardt (2000). Firm resources and sustained competitive advantage. Journal of Management, 17, 99-120.

Michailova W.S., and Husted, M., (2003). Breaking the myths of rewards: an exploratory study of attitudes about knowledge sharing. Information Resources Management Journal, 14, 14-21.

Halawi, L.W. (2005) Cultural ifluences on knowledge sharing communities through online communities of practice. Journal of Knowledge Management, 10, 94- 107. 